\title{
SOCIO-DEMOGRAPHIC VARIABLES AND RISK FACTORS OF TYPE 2 DIABETES AMONG URBAN RAJAHMUNDRY POPULATION
}

\author{
Madhavi N1, Chakravarthy D. J. K², Kiran Deedi M³, Ganapathi Swamy $\mathrm{Ch}^{4}$
}

${ }^{1}$ Lecturer, Department of Statistics, Government College (A), Rajahmundry, Andhra Pradesh, India.

${ }^{2}$ Assistant Professor, Department of General Medicine, GSL Medical College and General Hospital, Rajahmundry, Andhra Pradesh, India. ${ }^{3}$ Research Scholar, School of Life and Health Sciences, Adikavi Nannaya University, Rajahmundry, Andhra Pradesh, India. ${ }_{4}^{4}$ Assistant Professor, Department of Community Medicine, GSL Medical College and General Hospital, Rajahmundry, Andhra Pradesh, India.

\section{BACKGROUND}

\section{ABSTRACT}

In recent times diabetes has taken an epidemic form, having been seen in younger age group as well as in elderly. This may be due to improved nutritional status and decreased physical activity.

The objective of the study is to record the socio-demographic variables and risk factors of diabetes in urban areas of Rajahmundry, East Godavari district, Andhra Pradesh.

\section{MATERIALS AND METHODS}

A descriptive study was conducted from September 2015 to March 2016 for a period of 6 months in individuals of age ranging from 25 years to 80 years, who were either diabetic or non-diabetic among urban population of Rajahmundry, East Godavari district of Andhra Pradesh.

\section{RESULTS}

In our study population of 100 patients, male and female were 43 and 57 respectively with male-to-female ratio of 1: 1.3. The prevalence of diabetes was $21 \%$ in this study. Highest number of diabetics was found in the age group of 45 - 54 years. 52 out of 57 females were housewives, 2 were lecturers and 3 were daily labourers. Most of the males (22) were daily labourers. 64 subjects belonged to middle income group, 34 were of low-income group and 2 were of high-income group. 13 were habituated to smoking and 10 were alcoholic. 31 individuals were hypertensive among the study population.

\section{CONCLUSION}

Occupation, literacy, socio-economic status, hypertension, diet and exercise play a crucial role in the prevalence of the fast-growing non-communicable disease such as diabetes.

\section{KEY WORDS}

Diabetes, Hypertension, Occupation, Literacy, Diet.

HOW TO CITE THIS ARTICLE: Madhavi N, Chakravarthy DJK, Deedi KM, et al. Socio-demographic variables and risk factors of type 2 diabetes among urban Rajahmundry population. J. Evolution Med. Dent. Sci. 2018;7(40):4343-4346, DOI: $10.14260 /$ jemds/2018/969

\section{BACKGROUND}

India being proud as the developing nation is facing a huge challenge in the form of growing prevalence of noncommunicable diseases such as diabetes, hypertension, overweight and obesity. In the recent years, there is an increasing burden of diabetes in India. According to many studies India had been projected as the future capital of diabetes, which throws a threat to nation. In recent times, diabetes has taken an epidemic form resulting in presentation in younger age group as well as in elderly due to improved nutritional status and decreased physical activity.

'Financial or Other Competing Interest': Dr. Narasipuram reports grants from University Grants Commission, during the conduct of the study.

Submission 24-08-2018, Peer Review 17-09-2018,

Acceptance 24-09-2018, Published 01-10-2018.

Corresponding Author:

Chakravarthy D. J. K,

Assistant Professor

Department of General Medicine,

GSL Medical College and General Hospital,

Rajahmundry-533296,

Andhra Pradesh, India.

E-mail:drdjkc@gmail.com

DOI: $10.14260 /$ jemds/2018/969
With an increase in elderly population, there is proportionate increase in the prevalence of elderly individuals with diabetes. Diabetes complications involve all major vital organs of the body at some point during the course of the disease. Among the comorbidities, Hypertension (41.9\%) and cardiovascular disease $(28.1 \%)$ were relatively higher in elderly diabetics.[1] The Inter-Heart study showed that population attributable risk of acute myocardial infarction due to known diabetes was $10 \%$, implying that it is a major factor of risk.[2] The prevalence of coronary artery disease was $21.4 \%$ among diabetic subjects compared to 9.1\% in subjects with normal glucose tolerance.[3]

Occupation, literacy, diet, habituations such as smoking and alcohol consumption play a crucial and pivotal role in the development of diabetes and progress of the disease.[4] Nowadays, diet had become a major issue in the increasing prevalence of diabetes. With the growing technology and a sedentary lifestyle, many individuals are becoming overweight or obese. In North America and Europe, there is a growing trend of obesity from childhood because of the dietary habits and the availability of resources in technology added with lifestyle changes.[5] All these play an important role in the early onset of diabetes. 
In India, especially metro and the urban localities, there is an increasing prevalence and incidence of diabetes and hypertension, which has been evident in many publications and the recent national health census. This may be because of the migration, urbanisation and industrialisation.[6] Nowadays, there is an increasing availability of completely processed food in India as in western worlds, which might also be a factor for the increasing pace of non-communicable diseases. Indians are genetically predisposed for coronary artery disease due to lipid abnormalities.[7]

As we all know literacy plays an important role in the development of the nation, but because of sedentary occupation and decreasing exercises, we are racing towards non-communicable diseases along with the developing economy. Availability of junk food and high calorie diet is also an important factor.[8],[9],[10]

Objective of the study was to conduct and record the socio-demographic variables and the risk factors of diabetes in urban Rajahmundry, East Godavari district of Andhra Pradesh.

\section{MATERIALS AND METHODS}

This is a descriptive study. Required sample size was calculated by using the formula " $\mathrm{n}=4 \times \mathrm{P} \times \mathrm{Q} / \mathrm{L} \times \mathrm{L}$," where $\mathrm{P}$ is unknown prevalence and it was considered as $50 \%$. L is $20 \%$ allowable error of unknown prevalence (50\%) and then sample size was 100. Sampling method adopted was purposive sampling. Complete and relevant history was taken, history regarding drugs usage, alcohol, smoking and dietary habits were recorded and systolic and diastolic blood pressures were noted and subjected to investigations such as fasting and post-prandial blood sugars, to diagnose the individual as Diabetic according to WHO and ADA guidelines.

Study included all individuals ranging from age of 25 years to 80 years, who were either known diabetic or nondiabetic and subjected to investigations. Known diabetic was defined as an individual who had been diagnosed as diabetic in the past and presently using medications. The comatose patients and severely ill patients are not included in the study. Individuals suffering from other endocrine diseases and secondary hypertension are not included. The details collected are captured in a Master Chart and analysed.

All statistical analyses were done by using SPSS Software version 21.0 and MS Excel 2007. Descriptive statistical data was presented as mean \pm standard deviation and percentages. Chi-square test was performed to assess the association among various categorical variables. For all statistical analysis, $\mathrm{p}<0.05$ was considered as statistically significant.

\section{RESULTS}

Study was conducted in urban areas of Rajahmundry, East Godavari district, Andhra Pradesh with 100 individuals, who are selected over a period of 6 months. In this study, 43 are males and 57 are females. Highest age was 76 years. Male-tofemale ratio was 1: 1.3. Mean age of the study population was $46.41 \pm 11.35$ years. The mean age of diabetic individuals was $44.47 \pm 10.98$ years.

The prevalence of diabetes in our population was $21 \%$; 13 individuals are smokers and 10 individuals are alcoholic. The study population was divided into 4 groups of nondiabetic non-hypertensive (NDNH), diabetic hypertensive
(DH), diabetic non-hypertensive (DNH) and non-diabetic hypertensive (NDH) (Table 01).

The individuals included in the study were of various occupations including agricultural labourers, business, daily labourers, driver, electrician, government job, junior assistant, lecturer, private employee, student and housewives. 52 out of 57 females were housewives, 2 were lecturers and 3 were daily labourers. Most of the males (22) were daily labourers. The individuals of various professions were shown in Table 02. There was no statistical significance found between various professions and diabetes in our study.

64 subjects belonged to middle income group, 34 of lowincome group and 2 were of high income group (Table 03). Statistical significance was not found between diabetes and various income groups. The mean pulse rate of the study population was $81.27 \pm 9.22$ per minute. The mean systolic blood pressure of the study population was $121.73 \pm 16.95$ $\mathrm{mmHg}$ and diastolic blood pressure was $80.24 \pm 7.69 \mathrm{mmHg}$.

The mean height of the study population was $158.44 \pm$ 9.09 centimetres (cms). The mean weight of the study population was $63.97 \pm 11.91$ kilograms $(\mathrm{kg})$. The mean waist circumference of the study population was $11.91 \pm 13.82 \mathrm{~cm}$. The mean body mass index of the study population was 25.55 $\pm 4.92 \mathrm{~kg} /$ sq.m.

7 out of 13 smokers were diabetic and 5 were hypertensive. 3 smokers were non-diabetic and nonhypertensive. Smoking was found to be significantly associated with diabetes and hypertension. 5 out of 10 alcoholics were diabetic and 4 were hypertensive. 2 alcoholics were non-diabetic and non-hypertensive. Alcohol was found to be significantly associated with diabetes and hypertension (Table 01).

In our study 28 individuals were consuming fruits daily, whereas 43 were consuming once or twice in a week and 29 were rarely consuming fruits. 03 individuals out of 28 who were daily consuming fruits were diabetic. 04 out of 43 who were weekly consuming fruits were diabetic. 14 out of 29 who rarely consumed fruits were diabetic. Diabetes was found to be positively correlated with less amount of fruits intake. There was a significant association found between higher amount of fruit intake and lesser incidence of diabetes.

\begin{tabular}{|c|c|c|c|c|c|c|}
\hline & Total & NDNH & DH & DNH & NDH & \\
\hline \multicolumn{7}{|c|}{ Sex } \\
\hline Male & 43 & 23 & 10 & 3 & 7 & \\
\hline Female & 57 & 39 & 6 & 2 & 10 & 0.264 \\
\hline \multicolumn{7}{|c|}{ Age } \\
\hline $25-44$ years & 43 & 31 & 7 & 2 & 3 & \\
\hline 45-64 years & 50 & 29 & 8 & 3 & 10 & \\
\hline $64-80$ years & 7 & 2 & 1 & 0 & 4 & 0.062 \\
\hline \multicolumn{7}{|c|}{ Occupation } \\
\hline House wife & 52 & 36 & 5 & 2 & 9 & \\
\hline Daily labourer & 25 & 17 & 5 & 1 & 2 & \\
\hline Other occupations & 23 & 9 & 6 & 2 & 6 & 0.192 \\
\hline \multicolumn{7}{|c|}{ Socio-Economic Status } \\
\hline Middle income group & 64 & 40 & 9 & 3 & 12 & \\
\hline Low income group & 34 & 22 & 5 & 2 & 5 & \\
\hline High income group & 2 & 0 & 2 & 0 & 0 & 0.088 \\
\hline \multicolumn{7}{|c|}{ Fruits } \\
\hline Daily & 28 & 22 & 2 & 1 & 3 & \\
\hline
\end{tabular}




\begin{tabular}{|c|c|c|c|c|c|c|}
\hline Weekly & 43 & 33 & 3 & 1 & 6 & \\
\hline Rarely & 29 & 7 & 11 & 3 & 8 & 0.001 \\
\hline Smoking & 13 & 3 & 5 & 2 & 3 & \\
\hline Non-Smokers & 87 & 59 & 11 & 3 & 14 & 0.008 \\
\hline Alcohol & 10 & 2 & 4 & 1 & 3 & \\
\hline Non-Alcoholics & 90 & 60 & 12 & 4 & 14 & 0.032 \\
\hline
\end{tabular}

Table 1. Distribution of Type 2 Diabetes and Hypertension according to Age, Gender, Occupation, Smoking, Alcohol and Intake of Fruits

\begin{tabular}{|c|c|c|}
\hline Occupation & Frequency & Percent \\
\hline Agricultural labourer & 1 & 1 \\
\hline Business & 4 & 4 \\
\hline Daily labourer & 25 & 25 \\
\hline Driver & 3 & 3 \\
\hline Electrician & 5 & 5 \\
\hline Government employee & 3 & 3 \\
\hline Housewife & 52 & 52 \\
\hline Jr. Asst. & 2 & 2 \\
\hline Lecturer & 2 & 2 \\
\hline Private employee & 1 & 1 \\
\hline Student & 2 & 2 \\
\hline Total & $\mathbf{1 0 0}$ & $\mathbf{1 0 0}$ \\
\hline Table 2. Occupation of the Study Subjects \\
\hline \multicolumn{2}{|c}{} \\
\hline
\end{tabular}

\begin{tabular}{|c|c|c|}
\hline Socio-Economic Status & Frequency & Percent \\
\hline Middle income group & 64 & 64 \\
\hline Low income group & 34 & 34 \\
\hline High income group & 2 & 2 \\
\hline Total & $\mathbf{1 0 0}$ & $\mathbf{1 0 0}$ \\
\hline
\end{tabular}

Table 3. Distribution of Socio-Economic Status in the Study Population

\section{DISCUSSION}

Socio-demographic variables such as occupation, literacy, socio-economic status, food habits and lifestyle play an important role in the prevalence of diabetes and hypertension. The aetiology of diabetes is multi-factorial. Diabetes should not be considered as a professional illness. In many cases because of long working hours, shift duties and stress these people become more prone to noncommunicable diseases, especially diabetes and hypertension.[11] In our study, most of the females were housewives and males were daily wage labourers. There was no significant relation found between occupation and diabetes in the present study. There are many studies in India and abroad, some show positive correlation and some do not between occupation and diabetes.[12],[13],,[14],[15]

The allocation of health resources between various groups of people in society is disproportionate. There is wide variation of health awareness between various income groups and as well between various educational qualifications. There are various studies which showed inverse or direct relation between diabetes and household income.[16],[17] In the present study, no significant association was found between various income groups and diabetes.

Hypertension and diabetes are non-infectious diseases which are interrelated and had got a lot of significance. The prevalence of high blood pressure was $32.81 \%$ in middle income group and $29.41 \%$ in low income group. There are studies which have shown no relationship between socioeconomic status in association between hypertension and diabetes.[18]
Diabetes along with other non-communicable diseases is found to have a significant relation with the quantity, quality and nature of food which we consume. In our study, we have found a significant correlation between daily fruit intake and prevalence of diabetes. In our study, it was interestingly found that people who had a daily fruit intake had lesser prevalence of diabetes than who had a weekly and rare fruit intake.

Certain limitations are present in our study. Small sample size and recall bias form part of these limitations. Larger sample size is needed to generalise the findings in a larger perspective. The studies undertaken are also prone to potential error, because of heterogeneity of the Indian population with respect to culture and ethnicity.

\section{CONCLUSION}

Occupation, literacy, socio-economic status, diet and exercise play a crucial role in the prevalence of the fast-growing noncommunicable disease such as diabetes. Precautions which include lifestyle modifications, regular exercises and dietary habits need to be reviewed at regular time intervals. The potential catastrophic increase in diabetes at young age needs to be addressed. Further studies are required to provide more complete understanding of the differences in diabetes in relation to cultural and ethnic trends.

\section{REFERENCES}

[1] American Diabetes Association. Diagnosis and classification of diabetes mellitus. Diabetes Care 2009;32:S62-S7.

[2] Siddiqui AA, Siddiqui SA, Ahmad S, et al. Diabetes: mechanism, pathophysiology and management - a review. Int J Drug Dev \& Res 2013;5(2):1-23.

[3] Cade WT. Diabetes-related microvascular and macrovascular diseases in the physical therapy setting. Physical Therapy 2008;88(11):1322-35.

[4] Shi L, Shu XO, Li H, et al. Physical activity, smoking and alcohol consumption in association with incidence of type 2 diabetes among middle-aged and elderly Chinese men. PLoS One 2013;8(11): e77919.

[5] Ahmad QI, Ahmad CB, Ahmad SM. Childhood Obesity. Indian Journal of Endocrinology and Metabolism 2010;14(1):19-25.

[6] Kaveeshwar SA, Cornwall J. The current state of diabetes mellitus in India. Australas Med Journal 2014:7(1):45-8.

[7] Misra A, Khurana L. Obesity-related noncommunicable diseases: South Asians vs White Caucasians. Int J Obes (Lond) 2011;35(2):167-87.

[8] Ginter E, Simko V. Global prevalence and future of diabetes mellitus. Advances in Experimental Medicine and Biology 2012;771: 35-41.

[9] Olah ME, Gaisano G, Hwang SW. The effect of socioeconomic status on access to primary care: an audit study. Canadian Medical Association Journal 2013;185(6):E263-E9.

[10] Pereira MA, Kartashov AI, Ebbeling AB, et al. Fast-food habits, weight gain and insulin resistance (The CARDIA Study): 15-year prospective analysis. The Lancet 2005;365(9453):36-42. 
[11] Kawakami N, Araki S, Takatsuka N, et al. Overtime, psychosocial working conditions and occurrence of noninsulin dependent diabetes mellitus in Japanese men. J Epidemiol Community Health 1999;53(6):35963.

[12] Dyck R, Karunanayake C, Pahwa P, et al. Prevalence, risk factors and co-morbidities of diabetes among adults in rural Saskatchewan: the influence of farm residence and agriculture-related exposures. BMC Public Health 2013;13:7.

[13] Tharkar S, Kumpatla S, Muthukumaran P, et al. High prevalence of metabolic syndrome and cardiovascular risk among police personnel compared to general population in India. J Assoc Physicians India 2008;56:845-9.

[14] Ramachndran A, Snehalatha C, Yamuna A, et al. High prevalence of cardiometabolic risk factors among young physicians in India. J Assoc Physicians India 2008;56:17-20.
[15] Thabit H, Burns N, Shah S, et al. Prevalence and predictors of diabetes and cardiometabolic risk among construction workers in Ireland: the construction workers health trust screening study. Diab Vas Dis Res 2013;10(4):337-45.

[16] Corsi DJ, Subramanian SV. Association between socioeconomic status and self-reported diabetes in India: a cross-sectional multilevel analysis. BMJ Open 2012;2(4). pii: e000895.

[17] Zhang $\mathrm{H}, \mathrm{Xu} \mathrm{W}$, Dahl AK, et al. Relation of socioeconomic status to impaired fasting glucose and Type 2 diabetes: findings based on a large population-based cross-sectional study in Tianjin, China. Diabetic Medicine 2013;30(5):e157-e62.

[18] Rajput R, Rajput M, Singh J, et al. Prevalence of diabetes mellitus among the adult population in rural blocks of Haryana, India: a community-based study. Metabolic Syndrome and Related Disorders 2012;10(6):443-6. 